\section{Does Academic Commitment Affect The Learners' Progress Through Academic Buoyancy? A Structural Equation Model}

\author{
Iranian Evolutionary and Educational \\ Psychology Journal \\ September 2019: 196-203 \\ (C) University of Hormozgan Publication 2019 \\ DOI: 10.29252/ieepj.1.3.196 \\ http://ieepj.hormozgan.ac.ir
}

\author{
Parvin RezaeiGazki ${ }^{1}$, Ali Delavar2*, Abdolvahab Samavi ${ }^{3}$
}

\begin{abstract}
This study aims to test the pre-hypothesized model of the connection between these variables together. The research method was a correlational and structural equation modeling type. The statistical population consisted of all female pre-university students in Bandar Abbas in the educational year of 1396-1977 (1633 students) and the sampling method was multi - phase. The sample size was 600 people. Data collection tools were Hosseinchari and Dehghanizadeh Educational Well-being Questionnaire (391), and Human-Vogel \& Rabe Academic Commitment (2015), and an announced high school final exam score. 562 questionnaires were included in the study. Spearman correlation test and factor analysis in AMOS software were used for analysis. Results of a simple correlation between variables indicated a significant relationship between academic commitment and academic achievement $(\mathrm{r}=0.097, \mathrm{P} \leq 0.05)$, academic achievement and investment dimension $(\mathrm{R}=0.129, \mathrm{P} \leq 0.01)$, academic satisfaction and academic achievement dimension $(\mathrm{R}=0.098, \mathrm{P} \leq 0.05)$, and academic commitment to academic achievement level $(\mathrm{R}=0.147, \mathrm{P} \leq 0.01)$. There was also a significant relationship between the dimension of commitment replacement and educational achievement $(\mathrm{R}=0.132$, $\mathrm{P} \leq 0.01)$. The analysis of standard and non-standard coefficients showed that except for the relationship between the dimensions of commitment and the overall score of commitment that was expected, other ways were not significant. Despite the results above, the model fit indices (RMSEA, CFI, GFI, AGFI, NFI, IFI, IFI, TLI,) were favorable and indicated the average model fit to the data.
\end{abstract}

Keywords:Academic buoyancy, Academic commitment, Academic achievement, Student, School

\title{
Introduction
}

Academic achievement has always been one of the main concerns in the education system. Therefore, researchers try to discover effective factors to help improve it. These factors are either directly related to the learner or are factors associated with other variables in education including the teacher and the teaching method, and the socio-economic factors in the environment. The most important personal factors are motivation, self-efficacy, cognitive and other factors related to learner^s psychology (Kiyamanesh\&Meraji, 2011). One of the new trends in psychology is positive psychology capturing the attention of psychologists that one of its key constructs in the field of education is academic vitality (Rahimi\&Zareie, 2016).

Academic buoyancy refers to the positive, constructive, and adaptive response to different types of challenges and obstacles that are experienced in the continuous and ongoing field of study. These challenges include cases such as poor grades, deadlines, academic contests, exam pressure, and school problems (Martin \& Marsh, 2008; Putwain\& Daly, 2013).

This type of construct is positive, and research shows that it has a positive relationship to learning and academ-

1. Department of psychology, Bandar Abbas Branch, Islamic Azad University, Bandar Abbas, Iran.

2. Faculty of Psychology, AllamehTabatabai University, Tehran, Iran

*Corresponding author: delavarali@yahoo.com

3. Faculty of Humanities, Educational and Behavioral Researches Center, University of Hormozgan, Bandar Abbas, Iran 
ic performance of students (E ghadampour, radmehr, \& yousefvand, 2017; Malmberg, Hall, \& Martin, 2013; Martin, 2014; Miller, 2014 Connolly, \& Maguire, 2013; Pourabdol, Sobhi-Gharamaleki, \&Abbasi, 2015; Putwain, Connors, Symes, \& Douglas-Osborn, 2012; Putwain\& Daly, 2013; Strickland, 2015).

Fooladi, Kajbaf \& Ghamrani (2016), understood in the process of assessing the effectiveness of academic vitality education on academic meaning and academic performance of first grade female students that academic vitality training in post-test and follow-up stages cause significant improvement in academic meaning and academic performance of female students(Fouladi, Kajbaf, \&Ghmrani, 2018).

Malmberg et al. (2013), showed that academic vitality has a direct significant relationship with learning, while they were doing research on high school achievement and discovering the learning pattern,(Malmberg et al., 2013).

Pour-Abdel, Sobhi, and Abbasi (2015) conducted research to compare academic procrastination and academic buoyancy in students with and without specific learning disorders. The results showed that the low academic buoyancy in students with special learning disorders has an effective role in academic failure and as a result, the persistence of this disorder in these students (Pourabdol et al., 2015).

Miller et al. (2013) found in a study about examining the relationship between well-being and academic achievement in 7 to 11-year-old students in Northern Ireland that academic buoyancy correlated with students' academic performance (Miller et al., 2013). Strickland (2015) conducted a study at a Pennsylvania State Technical College to examine the relationships between academic vitality, motivation, and academic achievement of first-grade students. Specifically, the point was examined that academic buoyancy was a better predictor of academic achievement (as measured by standard GPA scores) than SAT and university proficiency scores. In the first part of the study, regression analysis showed that among the variables studied, only academic buoyancy was a small but significant predictor of academic achievement (Strickland, 2015).

In the first academic buoyancy studies in 2008, Martin and Marsh proposed three categories of health-related factors, including psychological factors, school, and commitment related factors, and family and peer-related factors as antecedents of academic vitality. (Martin \& Marsh, 2008). Martin et al. (2010) also introduced commitment, along with factors such as self-efficacy, planning, control, low stress as positive predictors of academic buoyancy (and significant predictors of academic buoyancy over time) (Martin, Colmar, Davey, \& Marsh, 2010).

Academic commitment is regarded as a new field of study within its broad and multidimensional meaning. The majority of the commitment studies are related to the areas of communication (Rosbelt, Maritza \&Angio, 1998) and organizational (Rose \& Gray, 2006), and academic commitment has only recently been studied (Viljoen, 2015). The academic commitment was initially conceptualized based on the percentage of practical effort and time devoted to educational and academic activity (Viljoen, 2015); but Human Vogel argues that the time and effort devoted to the study rarely reflect the comprehensiveness needed for the academic commitment in the study. He considered the commitment to include dimensions like meaningfulness, investment, alternative quality, satisfaction, and level of commitment (Human-Vogel, 2013). Other studies have shown a positive and significant relationship between the subscales of academic commitment, such as school satisfaction and academic buoyancy (AbedMoghaddam\&Raghagat, 2016), and it shows the effect of Logotherapy training on students' academic happiness and vitality (EzatollahGhadampour\&Kobra, 2017).

Sadri Damirchi, Karimianpour, and Jalilian (1396) conducted a study on predicting academic buoyancy based on psychological hardiness (as a variable that is one of the dimensions of academic commitment). The results of data analysis showed that there is a significant positive relationship between psychological hardiness and academic vitality, and 39\% of the changes in academic buoyancy are predictable based on perceptions of the learning environment and psychological hardiness (Sadri Damirchi, Karimaianpoor, \&Jalilan 2017).

On the other hand, studies show a link between commitment and academic achievement. In a study aimed at examining the types of undergraduate commitment levels and the relationships between these levels and important educational outcomes (such as perseverance, mental health), Wemak (2016) found that individuals with high academic and mental commitment showed less intention to leave the system and have lower mental health concerns and showed an increase in standardized scores (GPA) (Womack, 2016).

Goo and Maine's (2014) study of 557 university students being done to examine the relationship between professional commitment, learning participation, and academic achievement showed that professional commitment, learning participation, and academic achievement were positively correlated. Also, each of the di- 
mensions of emotional commitment, ideal commitment, continuous commitment, and emotional interaction had a positive impact on academic achievement (Y.-G. Liao \& Chen, 2014). Other studies of academic commitment also showed a positive relationship between professional commitment and student academic achievement (Y.-g. Liao \& Chen, 2014); indirect explanation of students' academic performance by meaningful commitment through psychological satisfaction ( Meiring, 2017); positive relationship of academic commitment to career wishes and academic wishes of the learners (Muala, 2018).

The Relationship between Academic buoyancy Education and Increasing Academic Meaning - As One Dimension of Academic Commitment (Fouladi et al., 2018; Isazadegan, Micaeili, \&Milan, 2014; Li et al., 2016; CN Liao \&Ji, 2015; Phan\&Ngu (2014), also demonstrates the importance of academic commitment in the field of learning and its relationship to academic achievement.

Given these relationships, it seems that academic commitment can mediate the relationship between academic buoyancy and academic achievement. Therefore, this study was designed to test the initial assumption model that showed the relationship between three variables of academic commitment, academic buoyancy, and academic achievement.

\section{Material and Methods}

The method of this research is Correlation and Structural Equation Modeling. Structural equation modeling is a statistical technique through which one can examine the causal relationships between current variables and test the model fit. The statistical population of the study consisted of all female pre-university students in Bandar Abbas (1633) in the educational year 2018. The reason for choosing this sample is the proximity to the college and school student population (as a medium population), and on the other hand, because of the new educational system, only the pre-university students receive a final exam score, In this population, the concern for the stability of the measurement instrument for academic achievement is lower than for the other students.

The sampling method was of multi-stage. At first, the cluster sampling and then stratified random sampling were used. Students' statistics were taken by district, the field of study and type of school and the ratios of each were calculated after coordination with Bandar Abbas Education Organization. This ratio was also observed in the selected sample. Thus, in each of the education districts, the sample size required in the empirical field of study in public schools, private schools, and nonprofits was calculated. This sample size was also calculated for math and human sciences. In each of the education districts, the available schools were listed by type of school (public, non-profit and private schools). From each of these districts, some schools were selected at random. Among the selected schools, the list of students was taken separately from the school management. Based on the sample size initially calculated for each class, students in each class were selected randomly (using Excel software).

To determine the sample size, Klein (2010) has proposed at least 5 people and optimally 20 people for each parameter in structural equation modeling research. Garver and Mentzer (1999) suggested a suitable sample size equal to 200 participants (Samavi, 2012). In this study, to get more assurance, the sample size was considered to be 600 people.

Finally, 562 questionnaires were entered into the study regarding the attendance and case following of the researcher.

Tools: The data collection tools in this study were the academic buoyancy and academic commitment questionnaires and the final exam score announced by the high school management. Hossein Chari and Dehghanizadeh scale (2012) was used to measure academic buoyancy that developed the Martin and Marsh (4) 4-item Academic buoyancy Questionnaire and made a 9-question questionnaire.

The Likert 5 was a choice from completely false to completely true. The minimum score in this questionnaire was 9 and the maximum was 45. The results of Hossein Chari and Dehghanizadeh (1391) study showed that the Cronbach's alpha coefficients obtained were favorable by omitting an equal item and the retest coefficient was acceptable. Also, the correlation coefficients of the items with a total score of $0 \%$ to $5 \%$ were reported indicating that the items had internal consistency and satisfactory stability (Dehghanizade \& Hoseinchari, 2012).

In the current study, Cronbach's alpha and split-half alpha were used to determine the stability of the scale. Also, to determine the validity of the students' academic buoyancy subscale, confirmatory factor analysis was 
performed on all items of this scale using the Moments of Structural Analysis (AMOS-22) software that all standard coefficients were above 0.40 . In other words, all of the items had a significant effect on one factor, namely academic buoyancy ( $\mathrm{p}<0.001$ ). The values of the RMSEA (root-mean-square error of approximation) fit indices were 0.054, as well as the fit indices of comparative fit index (CFI), goodness-of-fit (GFI), adjusted goodness-of-fit (AGFI), normed fit index (NFI), incremental fit index (IFI), Tucker-Lewis (TLI) above 0.9 (between 0.958 and 0.981 ) indicated approximately well fit of model with data.

The Hyman Vogel and Rabe (2015) questionnaire was used to measure academic commitment. The scale was first tested on 259 male students (52\% female and 47\%male) at the College of Engineering in South Africa. The questionnaire contained 30 questions and the functional structure of the questionnaire was declared satisfactory by its creators (Human-Vogel \&Rabe, 2015). The standardized study of the Persian version of this tool decreased the number of items to 25 . Cronbach's alpha of 0.698 to 0.898 , Spearman-Brown split of 0.683 to 0.867 , and Gutman split of 0.65 to 0.86 indicated the final acceptable stability of the tool (Rezaei, Samavi, \& Delavar, 2019). In this study, the values of the favorable RMSEA fit indices, as well as the fit indices of CFI, GFI, AGFI, NFI, IFI, TLI, (above 0.9), were reported as optimal which indicated that the model fit with the data. The Likert scale was rated as 5 (maximum score of 5 and a minimum of 1). The maximum score achievable in this questionnaire was 125 and at least was 25 . The questionnaire measures 5 subscales including meaningfulness (8 questions), investment (5 questions), alternative quality (3 questions), satisfaction, (5 questions) and level of commitment (4 questions).

\section{Results}

Of the 1,633 female pre-university students in Bandar Abbas, 1072 were in public schools, 203 in non-public schools, and 358 were in special schools including gifted and Shahid students. The number of students in Area 1 and 2 were 538 and 317 respectively, 186 and 139 in math, and 217 and 236 in humanities, respectively. In this study, the results of a simple correlation between variables showed a significant relationship between academic commitment and academic achievement (at a significant level of 0.05). Also, there was a significant relationship between the aspect of an investment, the academic satisfaction and the level of academic commitment, from the academic commitment aspects, with academic improvement at the significant level of 0.01, there was a significant relationship. The relationship between the commitment replacement aspect and academic achievement was significant at 0.05 level. Academic buoyancy showed a significant relationship only with the aspect of commitment replacement at the 0.01 level (Table 1)

Table 1. Simple correlation matrix of variables

\begin{tabular}{|c|c|c|c|c|c|c|c|c|}
\hline Variables & Index & $\begin{array}{l}\text { Aspect of } \\
\text { satisfaction }\end{array}$ & 7 & 6 & 5 & 4 & 3 & 2 \\
\hline \multirow{2}{*}{ Academic achievement } & $\mathrm{R}$ & 0.09 & 0.09 & 0.07 & 0.01 & 0.12 & 0.09 & 0.14 \\
\hline & Sig. & 0.02 & 0.02 & 0.08 & 0.74 & 0.002 & 0.03 & 0.001 \\
\hline \multirow{2}{*}{ 2- Aspect of level of commitment } & $\mathrm{R}$ & 0.47 & 0.55 & 0.01 & 0.30 & 0.32 & 0.30 & \\
\hline & Sig. & 0.001 & 0.001 & 0.65 & 0.001 & 0.001 & 0.001 & \\
\hline \multirow{2}{*}{$\begin{array}{l}\text { 3- Aspect of alternative quality of commit- } \\
\text { ment }\end{array}$} & $\mathrm{R}$ & 0.45 & 0.59 & 0.13 & 0.36 & 0.30 & & \\
\hline & Sig. & 0.001 & 0.001 & 0.002 & 0.001 & 0.001 & & \\
\hline \multirow{2}{*}{ 4- Aspect of Investment of commitment } & $\mathrm{R}$ & 0.55 & 0.71 & -0.03 & 0.43 & & & \\
\hline & Sig. & 0.001 & 0.001 & 0.39 & 0.001 & & & \\
\hline \multirow{2}{*}{ 5- Aspect of Meaningfulness of commitment } & $\mathrm{R}$ & 0.58 & 0.81 & -0.02 & & & & \\
\hline & Sig. & 0.001 & 0.001 & 0.58 & & & & \\
\hline \multirow{2}{*}{ 6- Academic buoyancy } & $\mathrm{R}$ & 0.04 & -0.031 & & & & & \\
\hline & Sig. & 0.34 & 0.46 & & & & & \\
\hline \multirow{2}{*}{ 7- Academic commitment } & $\mathrm{R}$ & 0.85 & & & & & & \\
\hline & Sig. & 0.001 & & & & & & \\
\hline
\end{tabular}

This study examined the assumptions of using AMOS software to check the hypotheses of the study. Normality was one of the assumptions of using structural equation modeling. Multivariate outliers were also checked $(C . R=2.49)$. According to the results in this study, there was no multicollinearity and the test of normality 
was non-significant.

Proposed model analysis:Examination of standard and non-standard coefficients shows that just academic buoyancy to academic commitment path was siginifcant (Table 2).

Table 2. Non-standard coefficients, standard error, critical ratio, significance level and standard coefficients

\begin{tabular}{|l|l|l|l|l|l|}
\hline Path & $\begin{array}{l}\text { Unstandard } \\
\text { Estimate }\end{array}$ & S.E & C.R. & $\begin{array}{l}\text { S t a n d a r d } \\
\text { Estimate }\end{array}$ \\
\hline Academic commitment to Academic buoyancy & -0.59 & 0.298 & -0.197 & 0.844 & -0.009 \\
\hline Academic commitment to Academic achievement & -0.33 & 0.017 & -1.895 & 0.058 & 0.079 \\
\hline Academic buoyancy to academic commitment & 0.311 & 0.123 & 2.522 & 0.012 & 0.115 \\
\hline
\end{tabular}

The model fit indices were also investigated. The RMSEA index and the fit indices of CFI, GFI, AGFI, NFI, IFI, TLI were favorable, indicating a nearly appropriate fit of the model to the data (Table 3).

Table 3. Goodnessof Fit Indexes

\begin{tabular}{|l|c|c|c|c|c|c|c|c|c|c|c|}
\hline Index & $\boldsymbol{\chi} \mathbf{2}$ & Sig. & DF & $\boldsymbol{\chi}^{2} / \mathbf{d f}$ & GFI & AGFI & NFI & CFI & IFI & TLI & $\begin{array}{c}\text { RM- } \\
\text { SEA }\end{array}$ \\
\hline Value & 38.154 & 0.001 & 13 & 2.935 & 0.981 & 0.990 & 0.953 & 0.968 & 0.968 & 0.978 & .059 \\
\hline
\end{tabular}

\section{Discussion}

The main purpose of this study was to examine an early model that shows that academic commitment can mediate the relationship between academic buoyancy and academic achievement. Although the factor analysis of this study did not confirm the default model, the results of a simple correlation between variables showed a significant relationship between academic commitment variable and academic achievement. Also, there was a significant relationship between the investment, substitution, the academic satisfaction aspects and the level of academic commitment, from the aspect of academic commitment with academic achievement.

In the case of the relationship between academic commitment and academic achievement, this study is inconsistent with the study of Rorik Vogel and Human Vogel (2016) (Vogel \& Human-Vogel, 2016) but it was in accordance with the studies of Goo and Maine, (2014); Moala, 2018; (Y.-g. Liao \& Chen, 2014; Muala, 2018; Womack, 2016). The findings of the study by Mirring (2017) also showed no association between meaningful commitment and academic achievement.

The results of this study, which examined the relationship between individual cognition of academic commitment and academic achievement in 11th and 12th-grade students at the University of South Africa, showed that meaningful commitment does not directly result in academic achievement (Meiring, 2017). In the present study, all aspects of academic commitment, except for the aspect of meaningfulness were correlated with academic achievement, and the variable that Meering (2017) assessed was semantic commitment. In this respect, these two studies can also be considered concordant (in the present study there was no significant relationship between meaningfulness and academic achievement). The relationship between overall commitment with academic achievement and the relationship of commitment subscales to academic achievement can be explained with the theory of academic commitment of Hyman Vogel and Rabe. This model is developed by Russell's (1998) Commitment Investment Model, which was created as the oldest model of marital commitment to study commitment in romantic relationships. According to this model, couples' commitment to each other depends on three interrelated factors. These factors include relationship satisfaction, relationship investment, and relationship alternatives. In other words, Russell believes that a spouse will commit to marriage once he is satisfied with his partner, invests heavily in his relationship, and has no other viable alternatives (Zarandi, Hashemianfar, \&Kianpour, 2017). The model is extended to various fields, including academic fields and can also explain academic commitment. Also, according to Hyman Vogel and Rabe (2014), in academic back- 
grounds, the most important theoretical framework that explains why students fail to achieve educational performance, includes self-regulation theory and student interaction. Self-regulation theories usually emphasize goal-oriented behavioral aspects, whereas learners' interaction framework focuses on behavioral indicators related to academic achievements such as time spent on doing homework and the quality of their effort. This result can also be explained together with the theory of Hellman and Williams Miller (2005). They described academic commitment as a multidimensional construct consisting of components of the psychological connection between the individual and the field of study. These elements include three elements of emotional, continuous, and normative connections. Emotional commitment indicates the emotional connection that individuals must have with student or college student identity. Individuals with high emotional commitment will or are more likely to behave in ways that reinforce and nourish their needs and social roles. The second link continuous commitment is an inclusive perception of cost analysis, utility, and stability in behavior as a student or student - (eg stable presence in class and continuous reading). The third link, normative commitment corresponds to the group values of the target audience or individual referenced and may include the acquisition of a specific level of training or degree (Viljoen, 2015).

The relationship between academic commitment and academic achievement can also be explained with the "tendency-to-school" theory (Maddox \& Prince, 2003). The tendency to the school is a multifaceted structure composed of the elements of commitment, power, belonging and belief in the rules. This element is a combination of learners' behaviors and beliefs about school. Beliefs include progress, planning for the future, getting good grades, and behaviors such as doing homework (Samavi, 2012). This relationship can be explained by Kubasa's theory of psychological hardiness. Using existing theories of personality, Kubasa defined hardiness as a combination of beliefs about oneself and the world, stemming from a coherent and coordinated practice of commitment, control, and struggle that provides the vision that creates courage, motivation and ability of the individual to grow personally and to control environmental stress (Azimi, 2016; Ramzi\&Besharat, 2010). From the viewpoint of Kubasa, a person who is highly committed believes in the importance of value and meaning of who he is and what he does (Azimi, 2016). In other words, commitment is described as a belief system that minimizes the perceived threat of life's difficult events. Kubasa believes that commitment is the most important factor in maintaining health. Commitment means being able to recognize a person's particular values, goals, and priorities, and to accurately assess the threat that a particular situation of life creates. In other words, the relationships of committed individuals with themselves and with their environment require being active and responsive rather than passive and denying(Azimi, (Azimi, 2016).

According to another finding of this study, academic buoyancy only showed a significant relationship with the commitment replacement aspect. Substitution then refers to what other alternatives a person has for studying, and if buoyancy can cope with the problems of everyday learners, one would expect that the fewer options there are for reading, the more acceptance seems to be created to deal with the common, everyday issues of education. According to another part of the study, there was no significant relationship between academic buoyancy and academic achievement among pre-university students in Bandar Abbas. These results are consistent with the results of the studies of Miller et al., 2013; Strickland, 2015; Martin, 2014; Malmberg, Hall \& Martin, 2013) Patwin and Dolly (2013) (Fouladi et al., 2018; E ghadampour et al., 2017; Malmberg et al., 2013; Martin, 2014; Miller et al., 2013; Putwain\& Daly, 2013; Strickland, 2015). In this respect, only the differences in the studied populations can be mentioned.

In spite of the above-mentioned studies, the partial study, Pourshafaei, and Mehdizadeh (1395) have been different (Bakhshi, Shafei, \&Mehdizadeh, 2016). According to the results of his study, even academic buoyancy had a negative effect on the educational performance of dormitory students of technical college.

Regarding the findings of the present study, which did not show a significant relationship between the two variables of academic buoyancy and academic achievement, it can be noted that the social construction of Bandar Abbas is composed mostly of travelers or non-native people who are living there because of their job. Similarly, a significant proportion of school students are non-native and live apart from their relatives. This may have little resemblance to the study population of Pourshafi and Mehdizadeh (2016), which was conducted on dormitory students.

In this study, there was no relationship between academic commitment and academic buoyancy. This result was inconsistent with the study of Martin et al. (2010), Lee, Ren, Ren, Zhou, Liu, and Zhang, (2016), Fan and Ngu, (2010) Chen Ning and Chan Ho (2010) (Isazadegan et al., 2014; Li et al., 2016; CN Liao \&Ji, 2015; 
Martin et al., 2010; Phan\&Ngu, 2014) but it was in accordance with the results of Carrington's (2013) study, which examined the predictive power of educational psychological factors for resiliency and academic buoyancy in 3D virtual learning environments (3D VLE)(Carrington, 2013). In this field, one can also refer to the socio-cultural differences of the populations and sample studied.

The results of this study showed a significant relationship between academic commitment variables and academic achievement. Also, there was a significant relationship between the investment, the substitution, the academic satisfaction dimensions, and the level of academic commitment, from the aspect of academic commitment with academic achievement. These results remind the planners 'attention to devising processes to enhance learners' academic commitment and increasing their satisfaction. Providing deeper studies in this area can also be helpful.

\section{Declaration of Conflicting Interests}

The author(s) declared no potential conflicts of interest with respect to the research, authorship, and/or publication of this article.

\section{Funding}

The author(s) received no financial support for the research, authorship, and/or publication of this article.

\section{References}

AbedMoghaddam, M., \& Raghagat, S. R. (2016). Explaining School Satisfaction: The Role of Academic High Schooling Students. Paper presented at the 4th National Conference on Counseling and Mental Health. https://www.civilica.com/Paper-MHWIAUQ04-MHWIAUQ04_354.html

Azimi, D. (2016). The Effectiveness of Teaching Psychological Hardiness Training on Academic Exercise and Social Acceptance. (Master's ). Allameh Tabatabaei University,

Bakhshi, F., Shafei, H., \& Mehdizadeh, I. (2016). The role of psychological capital and academic bouancy in the academic performance of dormitory and non-dormitory students of the girls' school in Birjand. Research approaches in the social sciences, 7, 283-274.

Carrington, C. C. (2013). Psycho-educational factors in the prediction of academic buoyancy in Second Life ${ }^{\circledR}$. Capella University,

Dehghanizade, M. H., \& Hoseinchari, M. (2012). Academic buoyancy and perception of family communication patterns; meditation role of self-efficacy Journal of Teaching and Learning Studies, 4(2), 21-47.

Fouladi, A., Kajbaf, M. B., \& Ghmrani, A. (2018). Effectiveness of Academic Buoyancy Training On Academic Success and Academic Self-Efficacy of Girl Students. Journal of Instruction and Evaluation, 11(42), 37-53. Retrieved from http://jinev.iaut.ac.ir/article_543431_4b6062dea00aaa5b7fbc04542157f846.pdf

Ghadampour, E., \& Kobra, B. (2017). The Effect of Logic Therapy Training on Happiness and Academic Life of Students. Cognitive Science News, 91, 1561-4174.

ghadampour, E., radmehr, P., \& yousefvand, L. (2017). The effect of group training based on Schneider hope theory on level academic engagement and hardiness girl students in first grade. erj, 3(33), 1-14.

Human-Vogel, S. (2013). A self-regulatory perspective on commitment in academic and interpersonal contexts. In Well-being research in South Africa (pp. 517-537): Springer.

Human-Vogel, S., \& Rabe, P. (2015). Measuring self-differentiation and academic commitment in University students: A case study of education and engineering students. SouthAfrican Journal of Psychology, 45(1), 60-70.

Isazadegan, A., Micaeili, F., \& Milan, F. M. (2014). The relationship between hope, optimism and meaning of education with academic performance in high school students. School Psychology, 2, 137-152.

Kayamanesh, A., \& Meraji, S. (2011). The role of self-concept of science, attitude towards science on the academic performance of science in students of the eighth grade of Iran and Sweden based on the data of TIMSS 2007. . Modern Educational Approaches, 6(14), 23-24.

Li, Y., Ren, Z., Ren, F., Zhu, Q., Liu, Y., \& Zhang, S. (2016). On the Relationship of Extraversion, Vitality and Meaning in Life among Chinese College Student.

Liao, C. N., \& Ji, C. H. (2015). The Origin of Major Choice, Academic Commitment, andCareer-Decision Readiness Among Taiwanese College Students. The Career Development Quarterly, 63(2), 156-170. 
Liao, Y.-g., \& Chen, M. (2014). College Students' Professional Commitment, Learning Engagement and Academic Achievements. Journal of SouthwestJiaotong University (Social Sciences)(4), 12.

Malmberg, L.-E., Hall, J., \& Martin, A. J. (2013). Academic buoyancy in secondary school: Exploring patterns of convergence in English, mathematics, science, and physical education. Learning and Individual Differences, 23, 262-266.

Martin, A. J. (2014). Academic buoyancy and academic outcomes: Towards a further understanding of students with attention-deficit/hyperactivity disorder (ADHD), students without ADHD, and academic buoyancy itself. British Journalof Educational Psychology, 84(1), 86-107.

Martin, A. J., Colmar, S. H., Davey, L. A., \& Marsh, H. W. (2010). Longitudinal modelling of academic buoyancy and motivation: Do the 5Cs hold up over time? British Journal of Educational Psychology, 80(3), 473-496.

Martin, A. J., \& Marsh, H. W. (2008). Academic buoyancy: Towards an understanding of students' everyday academic resilience. Journal of school psychology, 46(1), 53-83.

Meiring, C. J. (2017). The relation between academic commitment self-determination and academic achievement in Grade 11 and 12 learners. University of Pretoria,

Miller, S., Connolly, P., \& Maguire, L. K. (2013). Wellbeing, academic buoyancy and educational achievement in primary school students. International Journal of EducationalResearch, 62, 239-248.

Muala, S. A. (2018). The relation between academic commitment and vocational academic aspiration of university studants. Mustansiriyah Journal of Arts (MUJA), 70, 1:62. Retrieved from http://amm.uomustansiriyah.edu.iq/index.php/mustansiriyah/article/view/188

Phan, H. P., \& Ngu, B. H. (2014). An empirical analysis of students' learning and achievements: A motivational approach. Education Journal, 3(4), 203-216.

Pourabdol, S., Sobhi-Gharamaleki, N., \& Abbasi, M. (2015). A comparison of academic procrastination and academic vitality in students with and without specific learning disorder. Journal of learning disabilities, 4(3), 121-127.

Putwain, D. W., Connors, L., Symes, W., \& Douglas-Osborn, E. (2012). Is academic buoyancy anything more than adaptive coping? Anxiety, Stress \& Coping, 25(3), 349-358.

Putwain, D. W., \& Daly, A. L. (2013). Do clusters of test anxiety and academic buoyancy differentially predict academic performance? Learning and Individual Differences, 27, 157-162.

Rahimi, M., \& Zareie, E. (2016). The role of adult attachment dimensions in academic buoyancy through mediating the dimensions of self-efficacy of coping with problems and perfectionism. Research in School and Virtual Studies, 12, 59-70.

Ramzi, S., \& Besharat, M. (2010). The impact of hardiness on sport achievement and mental health. Procedia Social and Behavioral Sciences, 5, 823-826.

Rezaei, P., Delavar, A \& Samavi, S. A. (2019). Standardization of the Persian version of the Academic Commitment scale. Strides In Development of Medical Education: In press

Sadri Damirchi, E., Karimaianpoor, G., \& Jalilan, S. (2017). Prediction of Academic Buoyancy Based on Perception of Learning Environment and Psychological Hardiness in Medical Sciences Student. Bimonthly of Education Strategies in Medical Sciences, 10(5), 364-374. Retrieved from http://edcbmj.ir/article-11161-fa.html

Strickland, C. R. (2015). Academic Buoyancy as an Explanatory Factor for College Student Achievement and Retention.

Viljoen, B. (2015). The relationship between academic commitment and resilience for Education students at the University of Pretoria. (MAGISTER EDUCATIONIS (EDUCATIONAL PSYCHOLOGY)). University of Pretoria Faculty of Education Pretoria.

Vogel, F. R., \& Human-Vogel, S. (2016). Academic commitment and self-efficacy as predictors of academic achievement in additional materials science. Higher Education Research \& Development, 35(6), 12981310.

Womack, A. J. (2016). Profiles of Academic Commitment. ( Degree of Doctor of Philosophy). University of Southern Mississippiin Partial

Zarandi, M., Hashemianfar, S. A., \& Kianpour, M. (2017). Women and Social Engagement Marital Engagement; Case Study: Isfahan City. Culture Strategy, 129-163. 